Diabetes

Research

\& Care
BMJ Open

\section{Recovery of premorbid BMI trajectory without overshoot during the first year of treatment of children with type 1 diabetes}

\author{
Annika Grönberg, Ingemar Swenne
}

To cite: Grönberg A, Swenne I. Recovery of premorbid BMI trajectory without overshoot during the first year of treatment of children with type 1 diabetes. BMJ Open Diabetes Research and Care 2016;4:e000209. doi:10.1136/bmjdrc-2016000209

Received 9 February 2016 Revised 20 June 2016 Accepted 27 June 2016

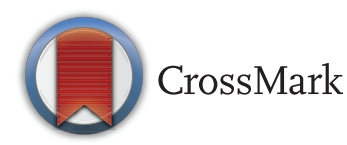

Department of Women's and Children's Health, Uppsala University, Uppsala, Sweden

Correspondence to Dr Annika Grönberg; annika.gronberg@kbh.uu.se

\section{ABSTRACT}

Objective: To study body mass index (BMI) changes and metabolic control in children and adolescents during the first year following the diagnosis of type 1 diabetes.

Research design and methods: 200 children and adolescents (<18 years) diagnosed with type 1 diabetes, started on multiple injection treatment and followed up for 1 year were studied with respect to metabolic control and weight change. Growth curves preceding the onset of diabetes were procured from the school health services. BMI was recalculated into BMI SD scores (BMISDS).

Results: Glycated hemoglobin ( $\mathrm{HbA} 1 \mathrm{c})$ at 1 year was $6.7 \pm 1.3 \%(50 \pm 10 \mathrm{mmol} / \mathrm{mol})$. HbA1c was positively correlated with daily insulin dose $\left(R^{2}=0.13 ; p<0.001\right)$, negatively correlated with age $\left(R^{2}=0.03 ; p<0.05\right)$ but not related to gender, BMISDS at 1 year, HbA1c at presentation, or ketoacidosis at presentation. Prior to the onset of diabetes, BMISDS was $0.41 \pm 1.20$ and decreased to $-0.63 \pm 1.25$ at presentation. BMISDS at 1 year was $0.54 \pm 0.97$ and not different from the premorbid value $(p>0.05)$. In a multiple regression analysis, BMISDS at 1 year was directly proportional to and highly predicted by BMISDS prior to onset of diabetes $\left(R^{2}=0.57 ; p<0.001\right)$. BMISDS at 1 year was also inversely correlated with age $\left(R^{2}=0.03 ; p<0.001\right)$ but could not be predicted by gender, daily insulin dose, $\mathrm{HbA} 1 \mathrm{C}$ at 1 year, $\mathrm{HbA1C}$ at presentation, or by ketoacidosis at presentation.

Conclusions: During the first year of treatment of type 1 diabetes in children and adolescents, it is possible to achieve good metabolic control without excess weight gain.

\section{INTRODUCTION}

At the start of treatment of newly diagnosed type 1 diabetes, there is rapid weight gain. ${ }^{1}$ This can initially be attributed to rehydration and normalization of the acute catabolic state of untreated type 1 diabetes. There is, however, a subsequent long-term trend for continuous excessive weight gain which may be considerable during pubertal development and especially so in girls. ${ }^{2-5}$ This weight gain has

\section{Key messages}

- Good metabolic control can be achieved during the first year following diagnosis with type 1 diabetes.

- There is rapid weight recovery following start of treatment.

- There is no overshoot in weight compared to premorbid growth trajectories.

repeatedly been associated with intensified insulin treatment. ${ }^{46}$ When focus is on maintaining blood sugar control, weight changes may be given lower attention or even be overlooked. This is of concern since excess weight gain causes adverse changes of cardiovascular risk factors ${ }^{6-9}$ and macrovascular lesions can be detected early in life in type 1 diabetes. ${ }^{10} 11$ At worst, overweight and increased cardiovascular risk could outweigh the beneficial effects of improved blood glucose control, cardiovascular events being a major determinant of excess mortality in type 1 diabetes. ${ }^{12}$

In studies of the short-term outcome of type 1 diabetes in children and adolescents, good metabolic control is usually achieved 1 year after presentation but weight/body mass index (BMI) is above population average. $^{1} 4{ }^{13-16}$ Premorbid weights and heights are, however, usually not available and it is unclear whether in these investigations findings represent excess weight gain during the first year of treatment or the children were constitutionally larger and heavier. At presentation of type 1 diabetes, there may be a history of overweight and increased linear growth, ${ }^{17}{ }^{18}$ but there are also several mechanisms by which type 1 diabetes and its treatment could cause excess weight gain. ${ }^{19} 20$ The objective of the present investigation was to analyze BMI changes and metabolic control in children and adolescents with type 1 diabetes during the first year of treatment. The primary aim was to compare BMI outcome with premorbid growth data. A 
secondary aim was to analyze whether BMI interferes with metabolic control. We hypothesized that the patients would recover their premorbid BMI trajectory early during treatment but that treatment-related factors could confer an additional risk for weight gain.

\section{RESEARCH DESIGN AND METHODS \\ Patients}

The pediatric diabetes team of Uppsala University Children's Hospital cares for all patients $<18$ years of age with diabetes in Uppsala county (population 341465 of which 69355 were under the age of 18 on 31 December 2012). This is a retrospective study for the period 20052012, when 216 children and adolescents born during 1988-2010 were diagnosed with type 1 diabetes, had treatment initiated, and were followed up for at least 1 year at the Children's Hospital.

\section{Procedure}

Since 2005, the Children's Hospital participates in the nationwide project 'Better Diabetes Diagnosis' (BDD), which was started to monitor newly diagnosed children and adolescents with type 1 diabetes for genetic predisposition and clinical phenotypes including BMI. ${ }^{21}$ Data on family history of diabetes and other autoimmune diseases, weight and height of parents, symptoms and signs of type 1 diabetes at the time of diagnosis, laboratory data at diagnosis and follow-up, and details of treatment were collected and registered in the Swedish Childhood Diabetes Registry (SWEDIABKIDS), a national incidence and quality control register. ${ }^{22}$ The diagnosis of type 1 diabetes was clinical and decided on before autoantibodies had been analyzed. The Karolinska Institute Research Ethics Board approved the study and informed, written consent was obtained from the parents.

The clinical diagnosis of type 1 diabetes did not have to be revised for any of the patients. One child was excluded from the analysis since the family discontinued insulin treatment for a period shortly after diagnosis. Another child with hemolytic anemia due to glucose-6phosphate dehydrogenase deficiency was excluded from analyses including measures of glycated hemoglobin (HbA1c). From SWEDIABKIDS, basal data for each patient at the time of diagnosis of type 1 diabetes were collected. This included age, gender, comorbid diseases diagnosed before the onset of diabetes, other family members with type 1 diabetes, and immigrant background. Weight, height, blood glucose, HbA1c, blood $\mathrm{pH}$, antibodies to transglutaminase IgA, thyroid peroxidase, and thyreoglobulin at the time of admission were registered. During the first year of treatment, weight, height, HbAlc, insulin dose (units/kg body weight/ day), proportion of bolus insulin (\% of daily dose), and the use of insulin pump were registered at 3, 6, and 12 months duration of disease. BMI $\left(\mathrm{kg} / \mathrm{m}^{2}\right)$ and BMI SD scores (BMISDS) were generated automatically by the SWEDIABKIDS register. ${ }^{23}$ Growth charts were procured from the school health services/childcare centers.
Two measurements of weight and height antedating by at least 3 months the diagnosis of diabetes were registered. Data including growth charts antedating the diagnosis of type 1 diabetes were available for 200 (93\%) patients who were included in the study.

Biochemical analyses were performed at the Department of Clinical Chemistry at the Uppsala University Hospital as part of the clinical follow-up of the patients. The laboratory is certified by a Swedish government authority (Swedac). Starting October 2010, HbA1c was analyzed according to the International Federation of Clinical Chemistry (IFCC) standard and expressed as $\mathrm{mmol} / \mathrm{mol}$. Prior to that date, analysis was according to the Mono $\mathrm{S}$ standard expressed in percent. In SWEDIABKIDS, analyses performed with the Mono S standard were recalculated using the expression HbAlc (IFCC; $\mathrm{mmol} / \mathrm{mol}$ ) $=10.45 \times \mathrm{HbA1c}$ (Mono S; \%) - 10.62. Presently, HbA1c is expressed in National Glycohemoglobin Standardization Program (NGSP) and IFCC standards (http://www.ngsp. org/convert1.asp).

\section{Treatment}

Treatment of type 1 diabetes was according to firmly established routines at the Uppsala University Children's Hospital and within the framework of the Swedish national programme for pediatric diabetes. ${ }^{24}$ All patients were hospitalized at presentation. For patients with severe ketoacidosis, treatment was started at an intensive care unit. The majority of the patients were admitted to a general pediatric ward together with a parent following a brief interview, physical examination, and blood sampling. Treatment was immediately started with intravenous insulin with the aim to normalize blood sugar concentrations. Intravenous insulin was discontinued after 2-2.5 days and the patients were started on a multiple injection therapy (MIT) regime with insulin aspart (NovoRapid) added to every meal and insulin detemir (Levemir) once daily at dinner time for basal insulin. A personalized meal schedule with three daily major meals and two-three snacks was introduced. Meals were initially of a set size and with a fixed insulin dose. Families were subsequently taught to adjust doses to different meal sizes. When treating hypoglycemic episodes, measurement of blood glucose and taking dextrose is emphasized to avoid excess caloric intake. From the very onset of MIT, the aim was (near) normal blood sugar concentrations $(3.5-7.5 \mathrm{mmol} / \mathrm{L})$ and a target $\mathrm{HbA} 1 \mathrm{c}<6.9 \%$ (52 $\mathrm{mmol} / \mathrm{mol}$ ). Families were taught that physical activity is part of treatment and children were encouraged to continue the physical activities they participated in prior to the diagnosis of diabetes.

Both parents were encouraged to take part in scheduled meetings with members of the diabetes team which consists of physicians, nurses, dieticians, and a clinical psychologist, all with training and experience in pediatric diabetes care. One aim of the training during the initial admission was to confer sufficient knowledge and practical ability to enable the families to return to their 
new everyday life. Another aim was to support the family and help them to meet the crisis of the abrupt and unexpected change in the family. In this context, it is notable that within the Swedish social security system parents can have reimbursed parental leave when caring for a sick child. Beginning at the end of the first week of admission and during the second week, the families were gradually transferred to home, school, and everyday life.

Following discharge from hospital after 7-15 days, a diabetes nurse was the primary contact of the family. The family attended $\sim 10$ outpatient visits to their diabetes nurse during the first year of treatment. Other members of the diabetes team participated when required. During this first year of treatment, there was continuous diabetes education and adaptation of the treatment regime to the patients' and families' needs. Blood glucose control was emphasised and vigilance over growth and weight development was maintained. Great emphasis was put on helping the family adapt to their new family life.

\section{Statistics}

Statistical analyses were performed with SPSS V.20.0.0. Data are given as means $\pm \mathrm{SD}$. A stepwise linear regression analysis was used for prediction of outcomes.

\section{RESULTS}

The 200 participants included in the study were at presentation of type 1 diabetes $9.3 \pm 4.4$ years old, $58 \%$ were male, $15 \%$ had at least one parent not born in Sweden, and $11.5 \%$ had type 1 diabetes in the primary family (table 1). Eight had celiac disease and four had

Table 1 Characteristics at presentation of 200 children and adolescents with type 1 diabetes

\begin{tabular}{ll}
\hline Male gender & $116(58 \%)$ \\
Age & $9.3 \pm 4.4$ \\
Born in Sweden & $196(98 \%)$ \\
One parent born outside Sweden & $30(15 \%)$ \\
Type 1 diabetes in primary family & $23(12 \%)$ \\
Previously diagnosed celiac disease & $8(4 \%)$ \\
Previously diagnosed hypothyreosis & $4(2 \%)$ \\
Body mass index SD score prior to & $0.41 \pm 1.20$ \\
presentation & \\
Body mass index SD score at & $-0.63 \pm 1.20$ \\
presentation & \\
Blood glucose (mmol/L) & $29.9 \pm 9.0$ \\
Glycated hemoglobin (\% (mmol/mol)) & $10.8 \pm 4.3(95$ \\
& $\pm 23)$ \\
Blood pH<7.3 & $45 / 197(23 \%)$ \\
Blood pH<7.2 & $23 / 197(12 \%)$ \\
Blood pH<7.1 & $9 / 197(5 \%)$ \\
Initial treatment at intensive care unit & $27(14 \%)$ \\
Positive for transglutaminase antibody & $12 / 162(7 \%)$ \\
Positive for thyroid peroxidase antibody & $13 / 133(10 \%)$ \\
Positive for thyreoglobulin antibody & $18 / 137(13 \%)$ \\
\hline
\end{tabular}

hypothyreosis diagnosed prior to the onset of type 1 diabetes. At diagnosis, HbAlc was $10.8 \pm 2.6(95 \pm 23 \mathrm{mmol} /$ $\mathrm{mol}$ ) and $22.8 \%$ had diabetic ketoacidosis (defined as $\mathrm{pH}<7.3$; table 1 ).

Three months after diagnosis, HbAlc had decreased to $6.2 \% \pm 1.1 \quad(44 \pm 8 \mathrm{mmol} / \mathrm{mol}$; figure $1 \mathrm{~A})$. $\mathrm{HbAlc}$ increased to $6.7 \pm 1.3 \% \quad(50 \pm 10 \mathrm{mmol} / \mathrm{mol} ; \mathrm{p}<0.001$ by one-sided analysis of variance) up to the 1 year follow-up. Treatment at 1 year was usually by MIT; only nine children used an insulin pump. Three months after diagnosis, the mean daily insulin dose was $0.69 \pm 0.20$ units/ $\mathrm{kg} /$ day. At 6 months, it was $0.72 \pm 0.2$ units $/ \mathrm{kg} /$ day, and at 1 year follow-up it had increased to $0.81 \pm 0.24$ units $/ \mathrm{kg}$ / day $(\mathrm{p}<0.001)$. At 1 year, $53 \pm 11 \%$ of the insulin dose was taken as a meal bolus; this proportion had not changed over the first year (table 2). A further 12 patients had been diagnosed with celiac disease and 3 with
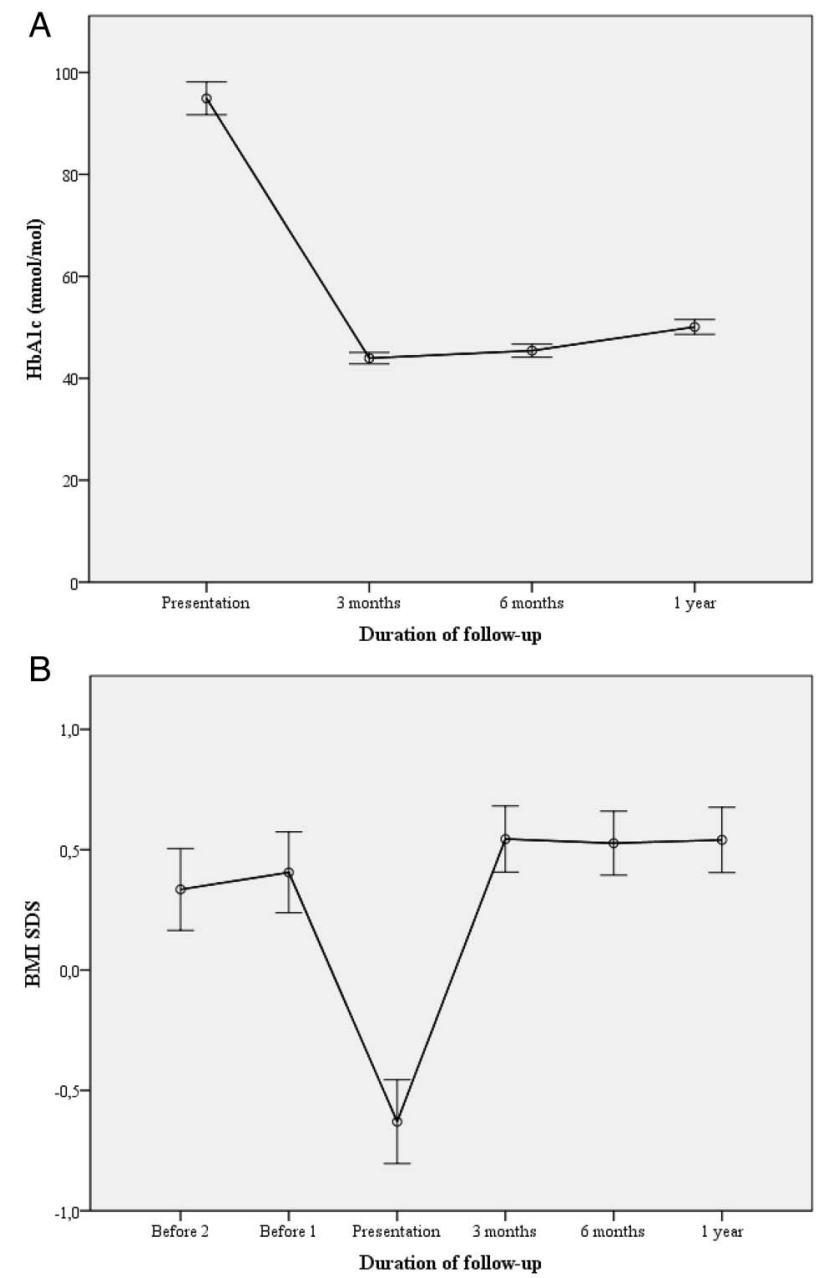

Figure $1 \mathrm{HbA1c}(\mathrm{A})$ and BMISDS (B) during the first year of treatment of type 1 diabetes in 200 children and adolescents. Values are means $\pm 95 \%$ Cls. BMISDS before the onset of type 1 diabetes is not significantly different from BMISDS during the first year of treatment ( $p>0.05$ by one-sided ANOVA). HbA1c increases during the first year of treatment $(p<0.001)$. ANOVA, analysis of variance; BMISDS, body mass index SD score; HbA1c, glycated hemoglobin. 
Table 2 Characteristics of 200 children and adolescents with type 1 diabetes at 1 year follow-up

\begin{tabular}{ll}
\hline Male gender & $116 / 84(58 \%)$ \\
Age & $10.37 \pm 4.4$ \\
Body mass index SD score & $0.54 \pm 0.97$ \\
Glycated hemoglobin (\%) & $6.7 \pm 3.1(50 \pm 10)$ \\
Insulin treatment & \\
Multiple injection therapy & $191(95.5 \%)$ \\
Pump & $9(4.5 \%)$ \\
Daily insulin dose (E/kg) & $0.81 \pm 0.24$ \\
Bolus insulin (\%) & $53 \pm 10$ \\
Celiac disease & $20(10 \%)$ \\
Hypothyreosis & $7(4 \%)$ \\
\hline
\end{tabular}

hypothyreosis during the first year of treatment. Patients with these comorbidities did not differ in the BMISDS or HbAlc at 1 year. There were no episodes of diabetic ketoacidosis and no episodes of severe hypoglycemia with unconsciousness or seizures.

Analysis of the growth charts from the school health services provided two measurements of BMISDS $1.5 \pm 1.5$ and $3.1 \pm 1.9$ years before the presentation of type 1 diabetes. The BMISDS was then $0.33 \pm 1.21$ and $0.41 \pm 1.20$, respectively (figure 1B). At presentation, BMISDS had decreased to $-0.63 \pm 1.25 \quad(\mathrm{p}<0.001)$. Following start of treatment, lost weight was recovered and already at 3 months BMISDS was $0.54 \pm 0.97$, close to the premorbid level. BMISDS remained at this level up to the 1 year follow-up. This was not significantly different from the premorbid values $(\mathrm{p}>0.05)$.

In a bivariate regression, BMISDS at 1 year was directly proportional to and highly predicted by BMISDS measured at the point closest prior to onset of type 1 diabetes $\left(R^{2}=0.54 ; \mathrm{p}<0.001\right.$; figure 2$)$. When BMISDS at 1 year was entered as the dependent variable in a stepwise linear regression analysis, it was positively predicted by BMISDS prior to onset $\left(\mathrm{R}^{2}=0.57 ; \mathrm{p}<0.001\right)$ and inversely by age $\left(\mathrm{R}^{2}=0.03 ; \mathrm{p}<0.001\right)$ but not by gender, insulin dose, percent bolus insulin, HbAlc at 1 year, or by $\mathrm{HbAlc}$ and $\mathrm{pH}$ at presentation. Analysis of the residuals did not indicate a curvilinear relationship between BMISDS prior to onset of type 1 diabetes and at 1 year follow-up (figure 2).

In a similar analysis, HbA1c at 1 year was positively predicted by the daily insulin dose at 1 year $\left(R^{2}=0.13\right.$; $\mathrm{p}<0.001)$, inversely by age $\left(\mathrm{R}^{2}=0.12 ; \mathrm{p}<0.001\right)$, and inversely by $\mathrm{pH}$ at presentation $\left(\mathrm{R}^{2}=0.02 ; \mathrm{p}<0.05\right)$ but not by gender, BMISDS at 1 year, or by BMISDS and HbAlc at presentation.

\section{CONCLUSION}

This study shows that it is possible to achieve good metabolic control without excess weight gain in children and adolescents with recently diagnosed type 1 diabetes. It is well established that following start of insulin treatment there is initially rapid weight gain but that the

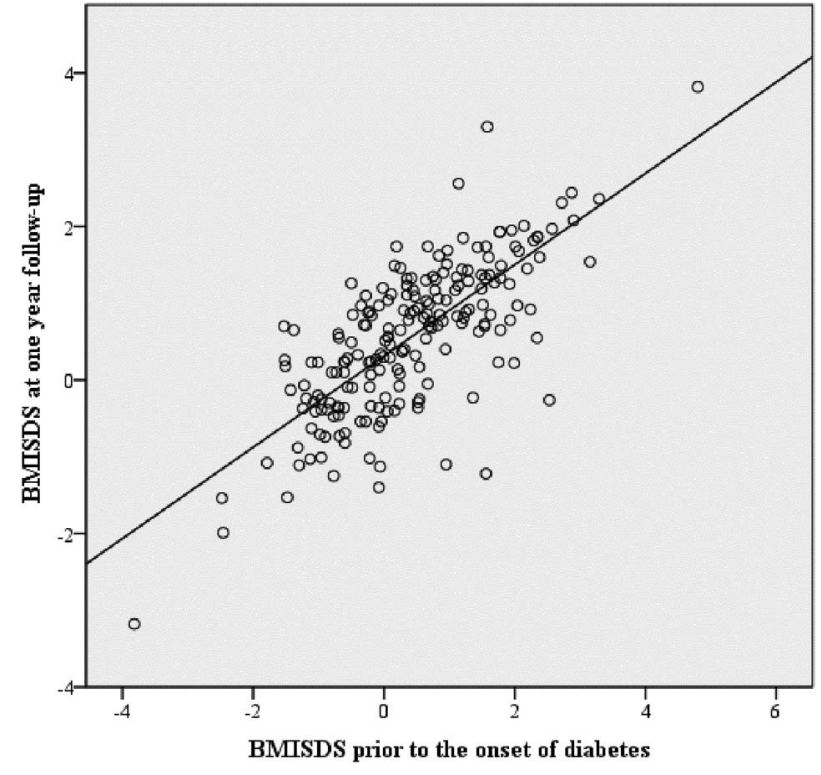

Figure 2 Correlation between BMI SD score prior to the onset of diabetes and at 1 year follow-up in 200 children and adolescents. The correlation is highly significant $\left(R^{2}=0.54\right.$; $\mathrm{p}<0.001)$. BMISDS, body mass index SD score.

increase of BMI levels off after the first few weeks/ months. ${ }^{1} 14152526$ Using objective growth data obtained prior to the onset of type 1 diabetes, it was possible to confirm the hypothesis that a stable BMISDS plateau is reached at the premorbid BMI trajectory without an upward trend suggesting future overweight. BMISDS was, however, above population average (ie, BMISDS $>0$ ) already prior to the onset of type 1 diabetes, in line with previous observations of a growth (rate) and BMI above average. ${ }^{15} 1718$ BMISDS at 1 year was highly predictable by the premorbid BMISDS but not to any large extent by other factors. In this context, it is notable that the relationship between BMISDS before onset of type 1 diabetes and at the 1 year follow-up was strictly linear, that is, there was no tendency for the more obese to overshoot their premorbid trajectory. Neither was there a tendency for the previously demonstrated excess weight gain in girls ${ }^{2} 327-30$ or with increasing age and pubertal development. ${ }^{3} 2830$ Altogether, this would suggest that BMISDS 1 year after the diagnosis of type 1 diabetes is to a large extent determined by hereditary factors ${ }^{31}$ and represents 'tracking', or following a predetermined developmental trajectory. Type 1 diabetes itself and its treatment can influence growth and development and cause excess weight gain. ${ }^{19}$ Presently, the disease-related and treatment-related factors investigated had little predictive value. Some aspects of the treatment regime presently endorsed could have helped to avoid excessive weight gain. The use of insulin detemir as basal insulin has been shown to promote stable weight compared with other basal insulins. ${ }^{32}$ The use of dextrose rather than foods for treatment of hypoglycemia limits excess energy intake at such occasions. Starting dietary 
treatment with basal carbohydrate counting and set meals decreases flexibility in food choice but maintains focus on both glycemic control and energy intake/ dietary quality. There is indeed some evidence to indicate that the full flexibility of advanced carbohydrate counting may promote weight gain even if blood glucose control is maintained. ${ }^{33}{ }^{34}$ Moreover, during the first year of treatment, the patients can be expected to have residual insulin production. This is delivered in the portal vein system, inhibits hepatic lipolysis better than peripherally administered insulin, and may cause less peripheral fat deposition. ${ }^{35}$ Altogether, these mechanisms can help to avoid unwanted weight gain. To this should be added that during the first year with type 1 diabetes the families are likely to adhere closely to the treatment regime. Treatment-related effects on BMI may therefore become apparent only later when adolescents/families develop their own course of lifestyle and diabetes management. ${ }^{36}$

The HbAlc level presently achieved at the 1 year follow-up compares favorably with previous studies. It was also confirmed that the nadir of HbAlc is reached early in the course of treatment, in this case at the 3-month control. There is subsequently a slow increase up to the 1 year control. ${ }^{1} 16252637$ This is not to say that metabolic control is lost since HbAlc still mirrors an ability to handle treatment well. It may rather reflect a successive loss of remaining endogenous insulin and a consequent increase in blood glucose excursions. The relationship between $\mathrm{HbAlc}$ and insulin dose at the 1 year control would also reflect this loss of endogenous insulin production. The association between higher $\mathrm{HbA1c}$ and lower age probably reflects the difficulties of achieving optimal blood glucose control in small children who also have a more rapid decline of their own remaining endogenous insulin production. ${ }^{25}$ Metabolic decompensation at presentation, as evidenced by low $\mathrm{pH}$, was weakly related to $\mathrm{HbAlc}$ at 1 year as previously shown, ${ }^{16} 25{ }^{37}$ although a parallel association with high HbAlc at presentation could not be demonstrated. The effect sizes, as evidenced by the $\mathrm{R}^{2}$ contributions, were low and only little of the variation of HbAlc was explained by these factors. It is more notable that female gender and weight/BMI, which are related to increasing HbAlc in longitudinal, long-term studies, $^{2} 282938$ were not related to HbAlc at the present 1 year follow-up. It may be that in the absence of such a gender-related and age-related weight gain, the increase with time of HbAlc is attenuated. This emphasizes the need to carefully monitor weight (changes), and not just blood glucose control, during the initial treatment of type 1 diabetes. Since weight gain inevitably depends on what is eaten, nutritional education of the family from the very start is thus essential. ${ }^{5}$

A strength of this study is the analysis of a large number of patients, treated at a single unit with a uniform treatment programme which has changed little over time and has an ambitious treatment target. ${ }^{39}$ There is a limitation in that some possible predictors of metabolic control and weight changes such as physical activity, Tanner staging of puberty, and measurements of $\mathrm{C}$ peptide were not available. These limitations, however, do not preclude the major conclusion of the absence of excess weight gain.

In conclusion, with the aid of growth charts from the school health services providing premorbid growth data, it was possible to demonstrate excellent metabolic control without excess weight gain 1 year after presentation of type 1 diabetes. The absence of excess weight gain may help to avoid early deterioration of cardiovascular risk factors. In the light of other longitudinal studies that have shown a successive increase of HbAlc with time concomitant with an excessive weight gain it would be important to extent the present study with a longer term follow-up.

Contributors AG and IS designed the study together. AG collected the data and created the database. The authors analyzed the data and drafted the manuscript together.

Funding This work was supported by the Swedish Child Diabetes Foundation (Barndiabetesfonden), Stiftelsen Sven Jerrings Foundation, Stiftelsen Samariten, Gillbergska stiftelsen, and Uppsala University.

Competing interests None declared.

Patient consent Obtained.

Ethics approval The Karolinska Institute Research Ethics Board.

Provenance and peer review Not commissioned; externally peer reviewed.

Data sharing statement No additional data are available.

Open Access This is an Open Access article distributed in accordance with the Creative Commons Attribution Non Commercial (CC BY-NC 4.0) license, which permits others to distribute, remix, adapt, build upon this work noncommercially, and license their derivative works on different terms, provided the original work is properly cited and the use is non-commercial. See: http:// creativecommons.org/licenses/by-nc/4.0/

\section{REFERENCES}

1. Newfield RS, Cohen D, Capparelli EV, et al. Rapid weight gain in children soon after diagnosis of type 1 diabetes: is there room for concern? Pediatr Diabetes 2009;10:310-15.

2. Gregory JW, Wilson AC, Greene SA. Body fat and overweight among children and adolescents with diabetes mellitus. Diabet Med 1992:9:344-8.

3. Danne T, Kordonouri O, Enders I, et al. Factors influencing height and weight development in children with diabetes. Results of the Berlin Retinopathy Study. Diabetes Care 1997;20:281-5

4. Fröhlich-Reiterer EE, Rosenbauer J, Bechtold-Dalla Pozza S, et al. Predictors of increasing BMl during the course of diabetes in children and adolescents with type 1 diabetes: data from the German/Austrian DPV multicentre survey. Arch Dis Child 2014;99:738-43.

5. de Vries L, Bar-Niv M, Lebenthal $Y$, et al. Changes in weight and BMI following the diagnosis of type 1 diabetes in children and adolescents. Acta Diabetol 2014;51:395-402.

6. Purnell JQ, Hokanson JE, Marcovina SM, et al. Effect of excessive weight gain with intensive therapy of type 1 diabetes on lipid levels and blood pressure: results from the DCCT. Diabetes Control and Complications Trial. JAMA 1998;280:140-6.

7. Marcovecchio ML, Dalton RN, Prevost AT, et al. Prevalence of abnormal lipid profiles and the relationship with the development of microalbuminuria in adolescents with type 1 diabetes. Diabetes Care 2009;32:658-63. 
8. Schwab KO, Doerfer J, Naeke A, et al, German/Austrian Pediatric DPV Initiative. Influence of food intake, age, gender, $\mathrm{HbA} 1 \mathrm{c}$, and BMI levels on plasma cholesterol in 29,979 children and adolescents with type 1 diabetes-reference data from the German diabetes documentation and quality management system (DPV). Pediatr Diabetes 2009;10:184-92.

9. van Vliet M, Van der Heyden JC, Diamant M, et al. Overweight is highly prevalent in children with type 1 diabetes and associates with cardiometabolic risk. J Pediatr 2010;156:923-9.

10. Urbina EM, Wadwa RP, Davis C, et al. Prevalence of increased arterial stiffness in children with type 1 diabetes mellitus differs by measurement site and sex: the SEARCH for Diabetes in Youth Study. J Pediatr 2010;156:731-1, 737.e731.

11. Krantz JS, Mack WJ, Hodis HN, et al. Early onset of subclinical atherosclerosis in young persons with type 1 diabetes. $J$ Pediatr 2004; 145:452-7.

12. Lind M, Svensson AM, Kosiborod M, et al. Glycemic control and excess mortality in type 1 diabetes. $N$ Engl $J$ Med 2014;371:1972-82.

13. Tuvemo T, Kobbah M, Proos LA. Growth and subcutaneous fat during the first five years of insulin-dependent diabetes in children. Acta Paediatr Suppl 1997;418:1-5.

14. Davis NL, Bursell JD, Evans WD, et al. Body composition in children with type 1 diabetes in the first year after diagnosis: relationship to glycaemic control and cardiovascular risk. Arch Dis Child 2012;97:312-15.

15. Bonfig W, Kapellen T, Dost A, et al, Diabetes Patienten Verlaufsdokumentationssystem Initiative of the German Working Group for Pediatric Diabetology and the German Bundesministerium für Bildung und Forschung Competence Net for Diabetes Mellitus. Growth in children and adolescents with type 1 diabetes. $J$ Pediatr 2012;160:900-3.e902.

16. Redondo MJ, Connor CG, Ruedy KJ, et al. Pediatric Diabetes Consortium Type 1 Diabetes New Onset (NeOn) Study: factors associated with $\mathrm{HbA1c}$ levels one year after diagnosis. Pediatr Diabetes 2014;15:294-302.

17. Hyppönen E, Virtanen SM, Kenward MG, et al, Childhood Diabetes in Finland Study Group. Obesity, increased linear growth, and risk of type 1 diabetes in children. Diabetes Care 2000;23:1755-60.

18. Ljungkrantz M, Ludvigsson J, Samuelsson U. Type 1 diabetes: increased height and weight gains in early childhood. Pediatr Diabetes 2008:9:50-6.

19. Russell-Jones D, Khan R. Insulin-associated weight gain in diabetes - causes, effects and coping strategies. Diabetes Obes Metab 2007:9:799-812.

20. Conway B, Miller RG, Costacou T, et al. Temporal patterns in overweight and obesity in type 1 diabetes. Diabet Med 2010;27:398-404.

21. Delli AJ, Lindblad B, Carlsson A, et al. Type 1 diabetes patients born to immigrants to Sweden increase their native diabetes risk and differ from Swedish patients in HLA types and islet autoantibodies. Pediatr Diabetes 2010;11:513-20.

22. Hanberger L, Samuelsson U, Lindblad B, et al, Swedish Childhood Diabetes Registry SWEDIABKIDS. A1C in children and adolescents with diabetes in relation to certain clinical parameters: the Swedish Childhood Diabetes Registry SWEDIABKIDS. Diabetes Care 2008;31:927-9.
23. Karlberg J, Luo ZC, Albertsson-Wikland K. Body mass index reference values (mean and SD) for Swedish children. Acta Paediatr 2001;90:1427-34.

24. Sjöblad S. Barn-och ungdomsdiabetes. 2nd ed. Lund, Sweden: Studentlitteratur $A B, 2008$.

25. Mortensen HB, Swift PG, Holl RW, et al, Hvidoere Study Group on Childhood Diabetes. Multinational study in children and adolescents with newly diagnosed type 1 diabetes: association of age, ketoacidosis, HLA status, and autoantibodies on residual beta-cell function and glycemic control 12 months after diagnosis. Pediatr Diabetes 2010;11:218-26.

26. Cengiz E, Connor CG, Ruedy KJ, et al. Pediatric diabetes consortium T1D New Onset (NeOn) study: clinical outcomes during the first year following diagnosis. Pediatr Diabetes 2014;15:287-93.

27. Bognetti $E$, Macellaro $P$, Novelli $D$, et al. Prevalence and correlates of obesity in insulin dependent diabetic patients. Arch Dis Child 1995;73:239-42.

28. Domargård A, Särnblad S, Kroon M, et al. Increased prevalence of overweight in adolescent girls with type 1 diabetes mellitus. Acta Paediatr 1999;88:1223-8.

29. Ingberg CM, Särnblad S, Palmér M, et al. Body composition in adolescent girls with type 1 diabetes. Diabet Med 2003;20:1005-11.

30. Sandhu N, Witmans MB, Lemay JF, et al. Prevalence of overweight and obesity in children and adolescents with type 1 diabetes mellitus. J Pediatr Endocrinol Metab 2008;21:631-40.

31. Holl RW, Heinze E, Seifert M, et al. Longitudinal analysis of somatic development in paediatric patients with IDDM: genetic influences on height and weight. Diabetologia 1994;37:925-9.

32. Nimri R, Lebenthal Y, Shalitin S, et al. Metabolic control by insulin detemir in basal-bolus therapy: treat-to-target study in children and adolescents with type 1 diabetes. Pediatr Diabetes 2013;14:196-202.

33. Nansel TR, Haynie DL, Lipsky LM, et al. Multiple indicators of poor diet quality in children and adolescents with type 1 diabetes are associated with higher body mass index percentile but not glycemic control. J Acad Nutr Diet 2012;112:1728-35.

34. Souto DL, Zajdenverg L, Rodacki M, et al. Impact of advanced and basic carbohydrate counting methods on metabolic control in patients with type 1 diabetes. Nutrition 2014;30:286-90.

35. Cleland SJ, Fisher BM, Colhoun HM, et al. Insulin resistance in type 1 diabetes: what is 'double diabetes' and what are the risks? Diabetologia 2013:56:1462-70.

36. Luyckx K, Seiffge-Krenke I. Continuity and change in glycemic control trajectories from adolescence to emerging adulthood: relationships with family climate and self-concept in type 1 diabetes. Diabetes Care 2009;32:797-801.

37. Bowden SA, Duck MM, Hoffman RP. Young children $<5 \mathrm{yr}$ ) and adolescents $(>12 \mathrm{yr}$ ) with type 1 diabetes mellitus have low rate of partial remission: diabetic ketoacidosis is an important risk factor. Pediatr Diabetes 2008:9(3 Pt 1):197-201.

38. Tylleskär K, Tuvemo T, Gustafsson J. Diabetes control deteriorates in girls at cessation of growth: relationship with body mass index. Diabet Med 2001:18:811-15.

39. Swift PG, Skinner TC, de Beaufort CE, et al. Target setting in intensive insulin management is associated with metabolic control: the Hvidoere childhood diabetes study group centre differences study 2005. Pediatr Diabetes 2010;11:271-8. 